\title{
New oscillatory electrocatalytic oxidation of amino compounds on a nanoporous film electrode of electrodeposited nickel hydroxide nanoflakes
}

\author{
Wei Huang, ${ }^{\dagger}$ Jufang Zheng, ${ }^{\S}$ and Zelin $\mathrm{Li}^{*},{ }^{\S}$ \\ ${ }^{\dagger}$ Key Laboratory of Chemical Biology and Traditional Chinese Medicine Research \\ (Ministry of Education of China), College of Chemistry and Chemical Engineering, \\ Hunan Normal University, Changsha 410081 China \\ ${ }^{\S}$ Zhejiang Key Laboratory for Reactive Chemistry on Solid Surfaces, Institute of \\ Physical Chemistry, Zhejiang Normal University, Jinhua 321004 China
}

\section{Supporting Information}

\footnotetext{
${ }^{*}$ Corresponding author. Tel.: +86-579-82283897; fax: +86-579-82282595.

E-mail address: lizelin@zjnu.cn.
} 
(1)

(2)

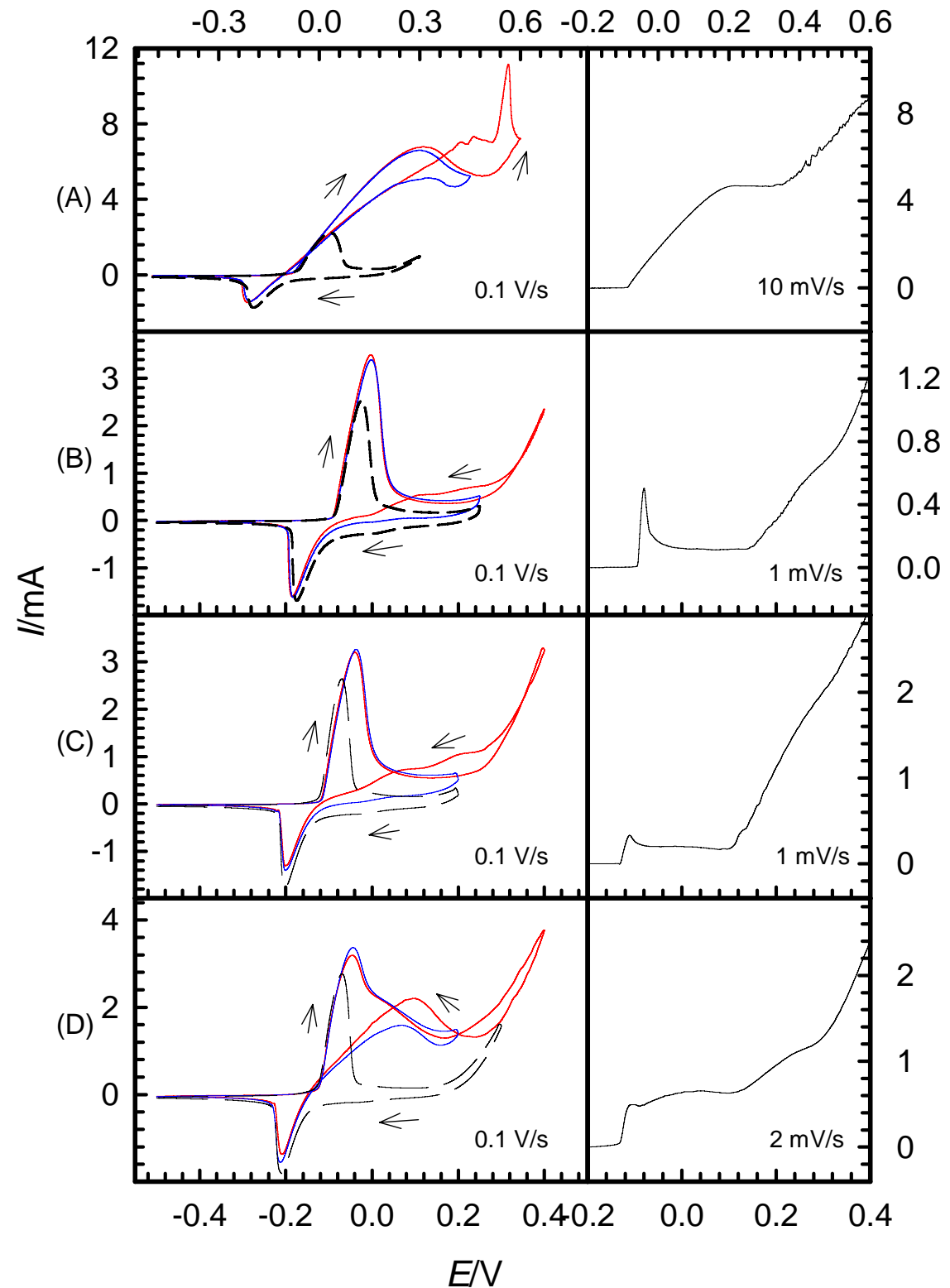

Figure S1. (1) Cyclic voltammograms without (blue solid lines) and with (red solid lines) oxygen evolution by setting different upper potential limits, and (2) steady-state polarization curves on the NHNF electrode for (A) $1 \mathrm{~mol} \mathrm{dm}^{-3}$ ETA $+1 \mathrm{~mol} \mathrm{dm}^{-3}$ $\mathrm{NaOH}$, (B) $0.1 \mathrm{~mol} \mathrm{dm}^{-3} \mathrm{Gly}+3 \mathrm{~mol} \mathrm{dm}{ }^{-3} \mathrm{NaOH}$, (C) $0.1 \mathrm{~mol} \mathrm{dm}^{-3} \mathrm{Ser}+3 \mathrm{~mol} \mathrm{dm}^{-3}$ $\mathrm{NaOH}$ and (D) $0.5 \mathrm{~mol} \mathrm{dm}^{-3} \mathrm{Arg}+3 \mathrm{~mol} \mathrm{dm}^{-3} \mathrm{NaOH}$ solutions. Thereinto the black dashed lines in (1) are CVs for the background solutions. 


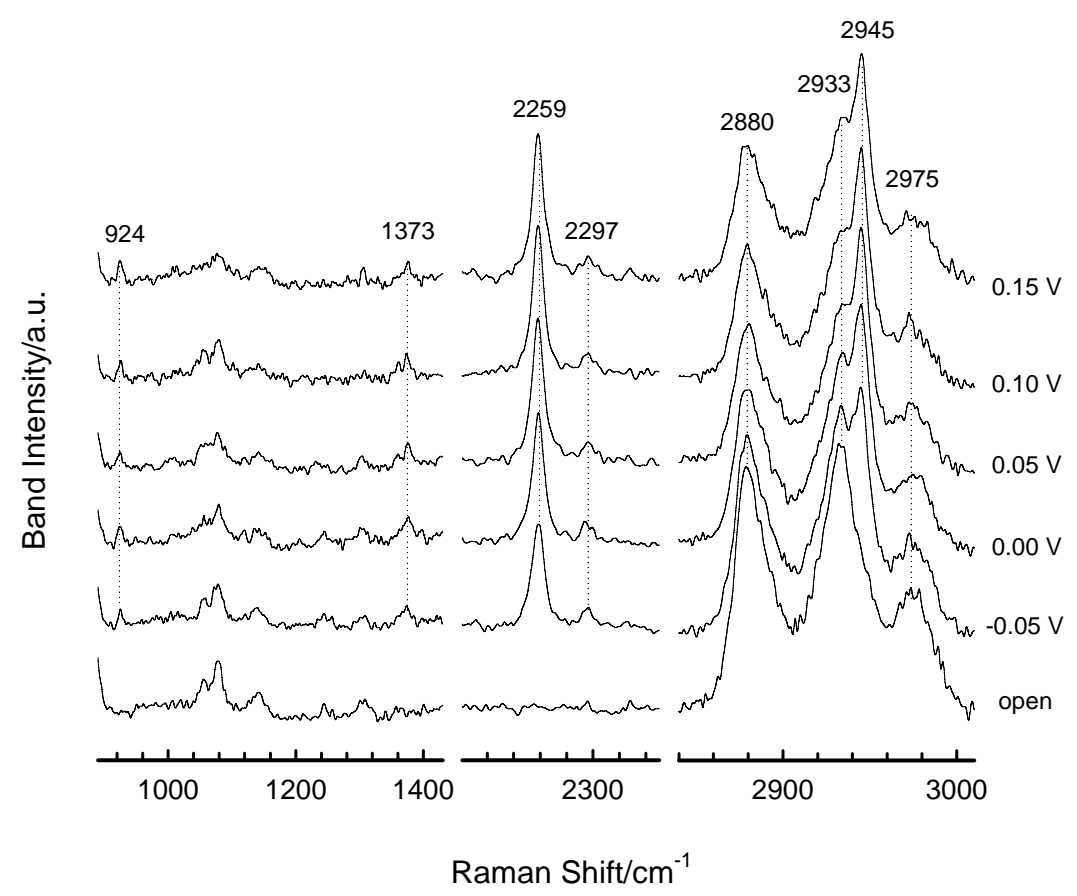

Figure S2. In situ Raman spectra at the distance about $100 \mu \mathrm{m}$ from the NHNF electrode with the same solution as in Figure S1(A) at different potentials. With potential increase from $-0.05 \mathrm{~V}$ to $0.15 \mathrm{~V}$, the ethylamine (the vibration bands at 2880 , 2933 and $\left.2975 \mathrm{~cm}^{-1}\right)^{1}$ is oxidized to acetonitrile (new features at 2259, 2297, 924, 2945 and $\left.1373 \mathrm{~cm}^{-1}\right) .^{2-3}$

Enantiomorphous concentration profiles between reactant ETA (2933 and 2880 $\left.\mathrm{cm}^{-1}\right)^{1}$ and product acetonitrile $\left(2259 \mathrm{~cm}^{-1}\right)^{4-5}$ in the diffusion layer at $0.2 \mathrm{~V}$, shown in Figures S3 and S4, confirm the diffusion-controlled process for electrooxidation of ETA. 


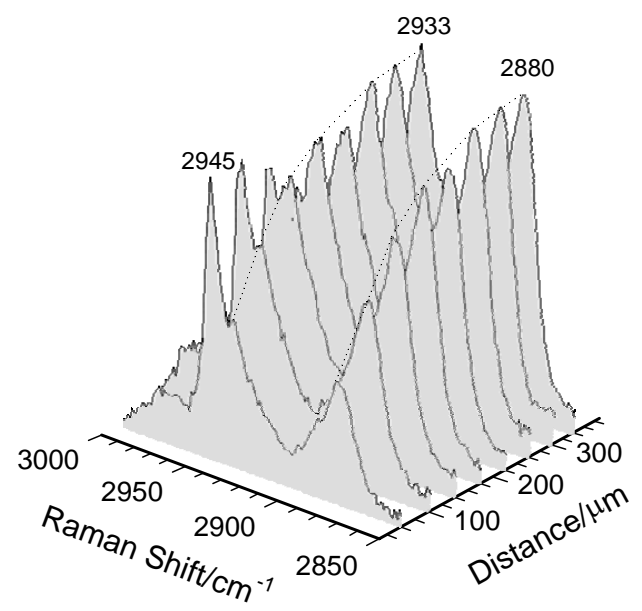

Figure S3. Spatial-resolved in situ Raman spectra during ETA oxidation at $0.2 \mathrm{~V}$ on the NNHF electrode. The exposure time for CCD is $100 \mathrm{~s}$. The dashed curve indicates the concentration profile of ETA in the diffusion layer.

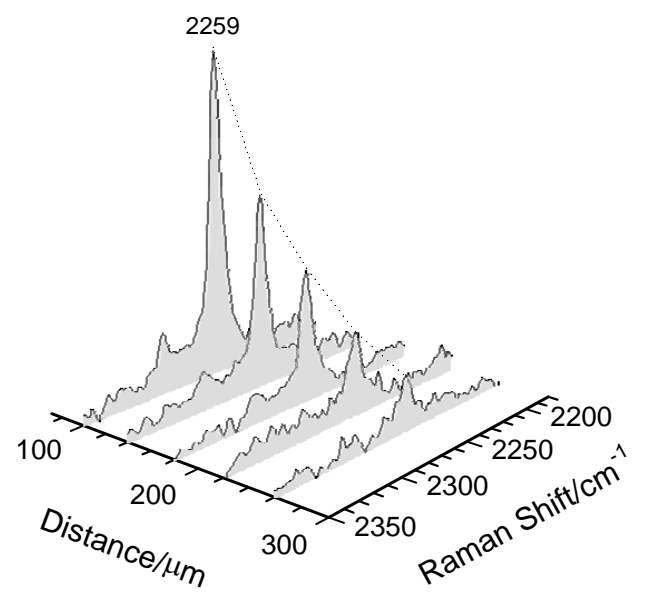

Figure S4. Spatial-resolved in situ Raman spectra during ETA oxidation at $0.2 \mathrm{~V}$ on the NNHF electrode. The exposure time for CCD is $100 \mathrm{~s}$. The dashed curve indicates the concentration profile of produced acetonitrile in the diffusion layer. 

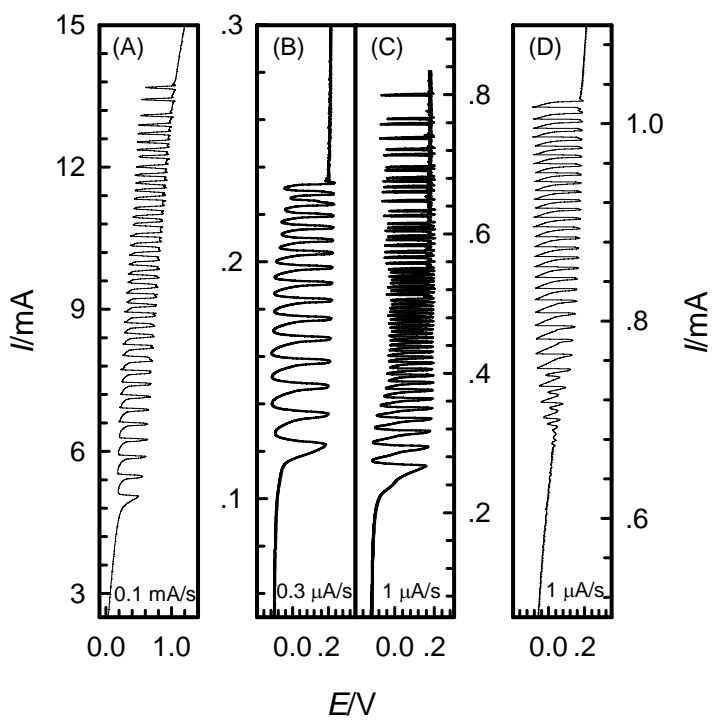

Figure S5. Current-potential curves obtained by current sweep on the NHNF electrode in (A) $1 \mathrm{~mol} \mathrm{dm}^{-3} \mathrm{ETA}+1 \mathrm{~mol} \mathrm{dm}^{-3} \mathrm{NaOH}$, (B) $0.1 \mathrm{~mol} \mathrm{dm}^{-3} \mathrm{Gly}+3 \mathrm{~mol}$ $\mathrm{dm}^{-3} \mathrm{NaOH}$, (C) $0.1 \mathrm{~mol} \mathrm{dm} \mathrm{dm}^{-3} \mathrm{Ser}+3 \mathrm{~mol} \mathrm{dm}^{-3} \mathrm{NaOH}$ and (D) $0.5 \mathrm{~mol} \mathrm{dm} \mathrm{dr}^{-3} \mathrm{Arg}+3$ mol dm ${ }^{-3} \mathrm{NaOH}$ solutions.

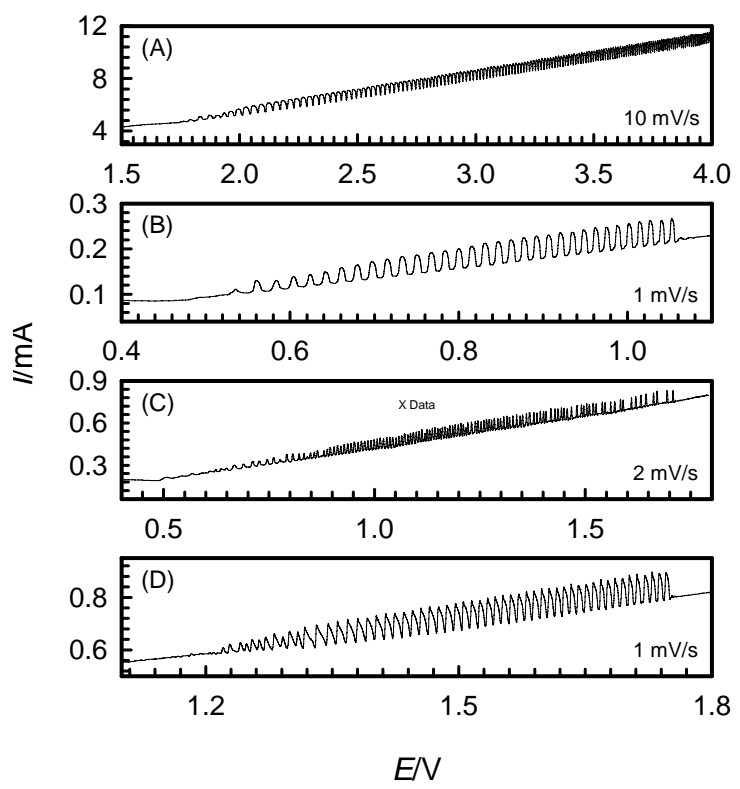

Figure S6. Current oscillations by potential sweep on the NHNF electrode in the same solution as in Figure S5 with different external resistances $R e(\Omega)$ : (A) 300; (B) 3000; (C) 2000; (D) 2000. 


\section{Supporting References}

(1) Zeroka, D.; Jensen, J.O.; Samuels, A.C. J. Mol. Struct. 1999, 465, 119-139.

(2) Goldstein, E.; Ma, B.; Lii, J.H.; Allinger, N.L. J. Phys. Org. Chem. 1996, 9, 191-202.

(3) Russo, N.D.; Khanna, R.K. Icarus 1996, 123, 366-395.

(4) Alía, J.M.; Edwards, H.G.M.; Moore, J. Spectrochim. Acta Part A 1995, 51, 2039-2056.

(5) Mosier-Boss, P.A. Spectrochim. Acta Part A 2005, 61, 527-534. 